\title{
Combined Therapy Effect of D-002 and Omeprazole on Chronic Esophagitis Induced by Duodenal Reflux in Rats
}

\author{
Zamora Z*, Mena L, Molina V, Pérez Y, Oyarzabal A, Noa M, Valle M, Jiménez S and Medina JA \\ Department of Pharmacology, Centre of Natural Products, National Centre for Scientific Research, Cubanacan, Havana, Cuba
}

*Corresponding author: Zamora Z, Department of Pharmacology, Centre of Natural Products, National Centre for Scientific Research. P Box 6880, Cubanacan, Havana, Cuba, Fax: +53-7-336837, Tel: +53-7-2714200, E-mail: zullyt.zamora@cnic.edu.cu

Citation: Zamora Z, Mena L, Molina V, Pérez Y, Oyarzabal A, et al. (2018) Combined Therapy Effect of D-002 and Omeprazole on Chronic Esophagitis Induced by Duodenal Reflux in Rats. J Gastroenterol Metabol 1: 106

Article history: Received: 27 December 2017, Accepted: 18 April 2018, Published: 20 April 2018

\begin{abstract}
Gastroesophageal reflux disease is a common gastrointestinal disorder. D-002 (beeswax alcohols) and omeprazole (OMP) present protective effects on esophagitis by reflux. In this study, the effect of combined therapy D002 + OMP on duodenum-esophageal reflux (DER) induced-esophagitis in rats was evaluated. Rats were randomized into five groups: one negative control and fourth groups with DER, including a positive control, two with D-002 and OMP (200 and $20 \mathrm{mg} / \mathrm{kg}$, respectively), and other with combination therapy D-002 + OMP $(200+20 \mathrm{mg} / \mathrm{kg}$, respectively). All treatments were orally administered for 14 days after DER. Esophageal lesions' index (ELI), Histological score (HS) and malondialdehyde (MDA) content in esophagus were determined. Positive controls exhibited increase ELI, HS and MDA in esophagus compared to negative controls. The combination therapy lowered significantly both ELI (48.05\%) and MDA (67.8\%) compared to positive controls, but without significant differences compared to their respective monotherapies. However, the combination therapy significantly reduced the HS respect to the positive control, reaching $96 \%$ inhibition, an effect that was higher than each of the monotherapies. In conclusion, the administration of the combination therapy (D-002 + OMP) represents an additional benefit in the protection of esophageal tissue with respect to treatment with monotherapies.
\end{abstract}

Keywords: D-002; Omeprazole; Rats; Duodenum Esophageal Reflux; Esophagitis; Malondialdehyde

List of abbreviations: OMP: Omeprazole; DER: Duodeno-Esophageal Reflux; MDA: Malondialdehyde; ELI: Esophageal Lesion Index; HS: Histological Score; GERD: Gastroesophageal Reflux Diseases; BE: Barrett' Esophagus; ADC: Adenocarcinoma; PPI: Proton Pump Inhibitors; HsRA: H2 Receptor Antagonists; BA: Bile Acids; ESI: Esophageal Sphincter Inferior, COX-2: Cyclooxygenase 2; PGE2: Prostaglandin E2; GDER: Gastro-Duodeno-Esophageal reflux

\section{Introduction}

Gastroesophageal reflux disease (GERD) occurs when the stomach and duodenum content are regurgitated into esophagus, causing mucosal lesions and esophageal tissue changes [1].

Gastroesophageal reflux leads to the adenocarcinoma (ADC) development that is one of its complications. In recent years the ADC incidence has increased faster than other tumors [2].

Numerous studies investigate the ADC formation mechanism from GER that include both gastric and duodenal juices refluxed $[3,4]$. However, differences between gastric and duodenal juice-induced damage was established, and non-acid (duodenal) reflux showed to be particularly important in the progression from Barrett's esophagus (BE) to ADC, confirming that duodenal juice may induce $\mathrm{EB}$ and $\mathrm{ADC}$ in rats $[5,6]$. So, the increase of $\mathrm{ADC}$ incidence is related to the acid suppression $[7,8]$.

There are evidences that bile acids (BA) short exposures to esophageal tissue induce oxidative stress, DNA oxidative damage, mutations, and apoptosis, whereas bile reflux long-term exposures lead to apoptosis resistance and eventually to develop ADC [913]. It has been shown that due to the apoptosis resistance, as an adaptive process, BE formation occurs depending on the severity of the reflux $[14,15]$.

GERD conventional therapy involves the use of anti-secretory drugs such as proton pump inhibitors (PPI) and H2 receptor antagonists (HsRA) [16,17]. 
Despite of PPI efficacy to treat GERD, there is still a substantial group of cases $(\approx 40 \%$ in some studies) who do not experience symptom relief with a standard PPI dose, due to transient lower esophageal sphincter relaxations, sensitivity to weakly acidic and/ or alkaline reflux, large volume of reflux and/or esophageal hypersensitivity [18-20].

As a consequence, the study of combined PPI and GABA receptor agonist drugs [ability to decrease the number of esophageal sphincter inferior (ESI) relaxations] was considered in experimental studies [21].

On the other hand, studies on physiopathological molecular process of esophagitis induced by biliary reflux have shown that BA activates gene transcription for enzyme cyclooxygenase 2 (COX-2) and prostaglandin E2 (PGE2) expression, confirming COX-2 expression and prostaglandins synthesis increase in dysplasia and esophageal cancer in rats, suggesting a possible mechanism of action [22-24]. Therefore, specific COX-2 inhibitors use, such as nimesulide as well as aspirin low doses have been effective as preventive of EB and ADC formation in DER experimental models [25,26].

For this reason, the search for effective and safe substances for the treatment of esophagitis by duodenum esophageal reflux (DER) is a current problem.

D-002, a mixture of six higher primary alcohols purified from the beeswax presents esophagus-protective effects through a multifactorial mechanism, without causing changes in the acid content of the gastric juice [27-30].

On the other hand, while D-002 showed an esophagus-protective effect in the chronic DER experimental model, it was ineffective in the gastro-duodenum-esophageal reflux (GDER) model [30]. Recently, D-002 efficacy on histopathological changes induced by DER esophagitis was demonstrated [31].

Based on these results, this study was aimed to investigate whether combination therapy of D-002 + OMP could ameliorate experimental esophagitis induced by DER in rats.

\section{Materials and Methods}

\section{Animals}

Male Sprague Dawley rats (270- 300 g) purchased from the National Centre for Laboratory Animals Production (CENPALAB, Havana, Cuba) were adapted for 7 days to the experimental conditions: temperature $25 \pm 2{ }^{\circ} \mathrm{C}$, humidity $60 \pm 5 \%$ and light/ dark cycles of $12 \mathrm{~h}$. Rats fed rodent pellet food produced in CENPALAB. Standard chow pellets from CENPALAB and water were given ad libitum, except during the $24 \mathrm{~h}$ prior to GER induction when food deprivation was applied, but water was provided ad libitum.

Animal experiments were performed according to the Cuban Guidelines for Animals Handling and the Cuban Code of Good Laboratory Practices (GLP), based on the Guide for the Care and Use of Experimental Animals (CCAC, 1993) [32]. The animal's protocols studies used were approved prior by the Institutional Board.

\section{Chemicals and test substance}

Omeprazole (OMP) was purchased from NOVATEC Laboratories, (Havana, Cuba). The batch of D-002, supplied by factory of Natural Products (Havana, Cuba), had the following composition: tetracosanol (7.0\%), hexacosanol (11.5\%), octacosanol (12.1\%), triacontanol (34.8\%), dotriacontanol (22.5\%) and tetratriacontanol (2.6\%). Purity (total content of these alcohols) was $90.0 \%$.

\section{Administration and dosage}

Both D-002 and OMP were suspended in a 1\% acacia gum/H2O vehicle. Rats were randomized into five groups of 10 rats each: a negative vehicle control and fourth with DER: a positive control treated with the vehicle, two with D-002 and OMP (200 and 20 $\mathrm{mg} / \mathrm{kg}$, respectively), and other with combination therapy D-002 plus OMP (200 plus $20 \mathrm{mg} / \mathrm{kg}$, respectively). All were given orally by gastric gavage ( $1 \mathrm{~mL} / 200 \mathrm{~g}$ of body weight), every $24 \mathrm{~h}$ for 14 days after inducing DER.

\section{DER-induced esophagitis}

DER was surgically induced according to the method of Hashimoto 2012 [23]. Solid foods were not allowed for $24 \mathrm{~h}$ before and $24 \mathrm{~h}$ after surgery. The esophagus-duodenum anastomosis was performed under general anesthesia (thiopental $30 \mathrm{mg} / \mathrm{kg}$ body weight) through an upper midline incision. The gastro esophageal junction was ligated and the distal esophagus was transected $2 \mathrm{~mm}$ above the ligature. Moreover, the gastro duodenal junction was ligated and the proximal duodenum was transected $3 \mathrm{~mm}$ distal to the pylorus. A total gastrectomy was performed and end-to-end anastomosis of the esophagus and duodenum was made. The abdominal incision was closed in two layers. Rats were euthanized under halothane atmosphere on day 14 after operation. The esophagus was removed, incised lengthwise and then the macroscopic esophageal lesions were quantified.

\section{Esophageal lesions index (ELI) determination}

The ELI was quantified by two independent blinded observers. ELI was estimated as the total area of damage observed under a magnifying glass with magnification $3 \mathrm{x}$ and expressed in $\mathrm{mm}^{2}$ [33]. 


\section{Histological Score (HS) determination}

Esophagus were washed with $0.9 \% \mathrm{NaCl}$ saline and fixed in $10 \%$ buffered formaldehyde. Samples from the lower $2 / 3$ of the esophagus, including the duodenum esophageal junction were taken and subsequently embedded in paraffin. Sections were stained with hematoxylin and eosin and examined using a Carl Zeiss Primo Star microscope.

The HS was determined by the presence of Edema, inflammatory infiltrate, epithelial thickening; on capillary growth and necrotic areas. The following score system was used for evaluation: unchanged (0); Discrete presence of changes (1); moderate (2) and severe changes (3) [33].

\section{Biochemical analysis}

\section{Tissue preparation}

The esophagus tissue was previously homogenized as follow. The excised esophageal tissue was transferred to ice-cooled test tubes and homogenized in $150 \mathrm{mmol} / \mathrm{L}$ Tris- $\mathrm{HCl}$ buffer $(\mathrm{pH}=7.4)$ containing $0.25 \mathrm{~mol} / \mathrm{L}$ sucrose-EDTA ( $1 \mathrm{~g}$ tissue/ $9 \mathrm{~mL}$ buffer) by Ultra-Turrax homogenizer T25 (Germany). The homogenates were centrifuged at $5000 \mathrm{~g}$ for $10 \mathrm{~min}$ at $4{ }^{\circ} \mathrm{C}$, and the supernatants stored at $-80^{\circ} \mathrm{C}$ until analysis. All the assays were performed in triplicate in an Ultrospec Plus LKB spectrophotometer (Pharmacia LkB Biotechnology; Uppsala, Sweden). Protein concentrations were measured by a modification of the Lowry method [34].

\section{Malondialdehyde (MDA) level (lipid peroxidation marker)}

MDA is reactive marker of membrane damage and forms a color complex with thiobarbituric acid (TBA) which can be measured spectrophotometrically. Herein, we measured the content of MDA using the method of TBARS assay [35]. In esophageal homogenates, thiobarbituric acid reactive species (TBARS) was measured. Firstly, homogenate aliquots (1 mL) were added to a mixture containing $0.2 \mathrm{~mL} 8.1 \%$ SDS plus $1.5 \mathrm{~mL} 20 \%$ acetic acid solution adjusted to $\mathrm{pH}=3.5,1.5 \mathrm{~mL}$ of thiobarbituric acid solution, and $1 \mathrm{mmol} / \mathrm{L}$ butylated hydroxytoluene, heated at $95^{\circ} \mathrm{C}$ for $45 \mathrm{~min}$ and cooled. One milliliter of distilled water plus $5 \mathrm{~mL}$ n-butanol: pyridine $(15: 1 \mathrm{v} / \mathrm{v})$ mixture was added to the mixture, shaken and centrifuged. The organic layer was used for TBARS determination at $535 \mathrm{~nm}$ using freshly diluted MDA bis (dimethyl acetal) as a standard. TBARS concentrations were expressed as $\mathrm{nmol} \mathrm{MDA} / \mathrm{mg}$ protein.

\section{Statistical analysis}

Data were expressed as the mean \pm SE. Paired comparisons between control and treated groups were done with the non-parametric Mann-Whitney U-test. The level of statistical significance was set at $\mathrm{p}=0.05$. The analyses were carried out by using the Statistic software for Windows (Release 4.2, Stat Soft, Inc USA). The results of esophagitis changes compared fisher test were used.

\section{Results}

Table 1 shows the effects of D-002, OMP and combination therapy orally administered during 14 days on ELI and histological score in esophageal tissue of rats with DER. As observed, the positive control group animals showed a significant increase of the ILE and the histological score with respect to negative control group, not subjected to DER.

\begin{tabular}{|c|c|c|c|c|c|}
\hline Groups & $\begin{array}{c}\text { Doses } \\
(\mathbf{m g} / \mathbf{k g})\end{array}$ & $\begin{array}{c}\text { ELI } \\
\left(\mathbf{m m}^{2}\right)\end{array}$ & $\begin{array}{c}\text { I } \\
(\%)\end{array}$ & HS & $\begin{array}{c}\text { I } \\
(\%)\end{array}$ \\
\hline Control (-) & - & $0.00 \pm 0.00^{* * *}$ & -- & $0^{* * *}$ & \\
\hline Control (+) DER & - & $322.00 \pm 53.89$ & -- & $1.96 \pm 0.10$ & \\
\hline DER + D-002 & 200 & $154.75 \pm 79.94^{* *}$ & 48,05 & $0.75 \pm 0.14^{* * *}$ & 61 \\
\hline DER + OMP & 20 & $194.75 \pm 93.35^{* *}$ & 60.5 & $0.37 \pm 0.06^{* * *}$ & 81 \\
\hline DER+ D-002 +OMP & $200+20$ & $191.00 \pm 71.43^{* * *}$ & 59.4 & $0.06 \pm 0.04^{* * * a b}$ & 96,6 \\
\hline
\end{tabular}

DER: Duodeno-esophageal reflux, I: inhibition; ELI: esophageal Lesion Index; HS: Histological score; OMP: omeprazole Data displayed as Mean \pm SEM (standard error of the mean)

${ }^{* *} \mathrm{p}<0.01 ;{ }^{* *} \mathrm{p}<0.001$; Comparison with Positive Control

a: $\mathrm{p}<0.01$ Comparison of combination therapy with OMP; $\mathbf{b}$ : $\mathrm{p}<0.001$ Comparison of combination therapy with D-002 (Mann Whitney U Test)

Table 1: Effects of D-002, OMP and combination therapy on ELI and histological score in esophageal tissue of rats with DER

D-002 (200 mg/kg), OMP (20 mg/kg) and its combination, markedly and significantly reduced the ELI reaching 48.1, 60.5 and $59.4 \%$ inhibition, respectively, although the effect achieved with the combined therapy was not significant with respect to each monotherapies.

In addition, the monotherapies D-002 (200 mg/kg) and OMP (20 mg/kg) markedly and significantly decreased (61 and $81 \%$ inhibition, respectively) the histological score compared to the positive control group. On the other hand, the combined therapy (D-002 and OMP) markedly and significantly reduced the histological score with respect to the positive control, reaching 96\% 
inhibition, an effect superior to that achieved with each monotherapy.

Table 2 shows the result of the effects of D-002, OMP and combination therapy on MDA concentrations in rat's esophageal tissue with DER. The DER induction produced a significant increase of MDA content in the esophageal tissue of the positive control group animals with respect to negative control group. The effect obtained on the increase of MDA levels with each of the monotherapies (D-002 and OMP) was marked and significant, reaching a percentage of inhibition of 69.8 and $75.2 \%$, respectively, although the combination therapy did not produce an additional effect on this variable.

\begin{tabular}{|c|c|c|c|}
\hline Groups & $\begin{array}{c}\text { Doses } \\
(\mathbf{m g} / \mathbf{k g})\end{array}$ & $\begin{array}{c}\text { MDA } \\
(\mathbf{n m o l} / \mathbf{m g ~ p t})\end{array}$ & $\begin{array}{c}\text { I } \\
(\%)\end{array}$ \\
\hline Control (-) & - & $2,43 \pm 0,15^{* * *}$ & - \\
\hline Control (+) DER & - & $3,93 \pm 0,63$ & - \\
\hline DER + D-002 & 200 & $2,88 \pm 0,65^{*}$ & 69,8 \\
\hline DER + OMP & 20 & $2,80 \pm 0,33^{* *}$ & 75,2 \\
\hline DER+ D-002 +OMP & $200+20$ & $2,91 \pm 0,39^{* *}$ & 67,8 \\
\hline
\end{tabular}

DER: Duodeno-esophageal reflux; I: inhibition; MDA: malondialdehyde; OMP: omeprazole; pt: protein

Data displayed as Mean \pm SEM (standard error of the mean)

${ }^{\star} \mathrm{p}<0.05 ;{ }^{* *} \mathrm{p}<0.01 ;{ }^{* *} \mathrm{p}<0.001$; Comparison with Positive Control

(Mann Whitney U Test)

Table 2: Effects of D-002, OMP and combination therapy on MDA concentrations in esophageal tissue of rats with DER

\section{Discussion}

Oral administration with the combination of D-002 + OMP (200 mg/kg and $20 \mathrm{mg} / \mathrm{kg}$, respectively) during 14 days after DER induction, markedly and significantly inhibited the ELI, although it did not reach significant differences with respect to monotherapies. However, the effect achieved with the combined therapy on the histological score was significantly higher than that achieved with each of the monotherapies.

This apparent contradiction could be explained by the differences in the macroscopic and microscopic variables measured. Thus, ELI constitutes a measure of the superficial extent of the damaged area while the histological score was established based on the edema severity, inflammatory infiltrate, epithelial thickening, capillary overgrowth and necrotic areas.

Taking into account that the efficacy of the combination therapy D-002 + OMP in esophagitis induced by the DER is based on histological score reduction it represents an additional benefit on the esophageal tissue protection with respect to their monotherapies. Therefore, these results suggest that the combination therapy by reducing the degree and severity of esophageal tissue damage could prevent the development towards chronicity of intrinsic inflammatory esophagitis. Recent results demonstrated that repeated doses of D-002 ameliorated the histological changes in rats with DER-induced esophagitis, those are in alignment to ours reports [31].

The severity of an esophageal ulcer has been correlated with the overproduction of free radicals. Oxidative stress (OS) is caused when production of reactive oxidative species (ROS) exceeds the potential of cellular antioxidant defenses to detoxify these toxicants [36]. And then, esophageal ulcer by the continuous and chronic reflux progresses gradually and can deteriorate until esophageal stricture or Barret's esophagus. Ultimately, it may contribute to the development of esophageal cancer [37]. OS can be determined by measuring the levels of malondialdehyde (MDA), which is a lipid peroxide generated by the reaction among oxygen free radicals [38].

Precedent studies have unfolded the role of free radicals in pathogenesis of GERD in experimental animals with concomitant increase in levels of malondialdehyde (MDA) [39]. MDA is a stable product of lipid peroxidation and is a sensitive and reactive marker of membrane damage. In the present study, we observed an increase in the esophageal MDA content that corroborates ROS participation after the esophagus-duodenal anastomosis in alignment with previous reports [40]. It would be apropos to mention that D-002 and its combination with OMP decreased lipid peroxidation as evidenced by the decrease in the MDA formation through the TBA assay. DER induction produced a marked damage on the lipid structures (tissue MDA contents) in animals submitted to duodenal reflux, according to observed in previous studies [41].

The increase in MDA levels, as an indicator of oxidative damage to lipids, has been evidenced in different experimental models of chronic esophagitis $[29,42,43]$, results that are in correspondence with those demonstrated in our study. Therefore, duodenal reflux may act as a co-carcinogen in esophageal squamous cell pathogenesis in rats, which may be mediated by oxidative stress [44].

Oral administration of D-002 (200 mg/kg), OMP (20 mg/kg) and the combination therapy D-002 + OMP decreased tissue MDA concentrations, without differences between the combined therapy and monotherapies in correspondence with previous studies $[30]$. 
Recently it was demonstrated that DER induction promotes MDA concentration increase in esophagus tissue, accompanied by a reduction in the superoxide dismutase (SOD), catalase (CAT) and glutathione peroxide (GPx) activities as well as glutathione (GSH) levels, while that the antioxidant activity of D-002 and OMP that support their esophagus protective effect involves a stimulation of these enzymatic activities and an GSH levels increase $[36,45]$.

Previous evidence shows that D-002 has been effective in protecting against acute and chronic GER-induced esophagitis and chronic DER (14 days), even in combination with OMP, as was demonstrated in these results [28-31]. However, we must emphasize that protective activity of D002, shown in the present study, was not sufficient to inhibit esophageal damage induced by DGER, where the damage is potentially greater given the presence of acid and bile reflux (mixed) [30]. It was reported that the OMP, classical PPI, decreases some components of refluxed bile acids, which supports its efficacy in this experimental model [46].

The results of this present study showed for the first time the esophago-protective efficacy of D-002 associated with a reduced level of MDA in esophageal tissue of rats with DER-induced esophagitis, suggesting later studies on the action of D-002 treatment and its combination with OMP on the enzymatic antioxidant systems in experimental duodenal esophagitis.

In conclusion, this study demonstrated that the oral administration with the combination therapy D-002 + OMP markedly and significantly reduced the histological score of damage in esophageal tissue with respect to the positive control, reaching $96 \%$ inhibition, an effect that was higher than that achieved with each of the monotherapies, representing an additional benefit in the protection of this tissue.

\section{References}

1. Armstrong D, Sifrim D (2010) New pharmacologic approaches in gastroesophageal reflux disease. Gastroenterol Clin North Am 39: 393-418.

2. Holmes RS, Vaughan TL (2007) Epidemiology and pathogenesis of esophageal cancer. Semin Radiat Oncol 17: 2-9.

3. Herbella FA, Patti MG (2010) Gastroesophageal reflux disease: From pathophysiology to treatment. World J Gastroenterol 16: 3745-9.

4. Ahiri S, Singh P, Singh S, Rasheed N, Palit G, et al. (2009) Melatonin protects against experimental reflux esophagitis. J Pineal Res 46: 207-13.

5. Miyashita T, Ohta T, Fujimura T, Ninomiya I, Fushida S, et al. (2006) Duodenal juice stimulates oesophageal stem cells to induce Barrett's oesophagus and oesophageal adenocarcinoma in rats. Oncol Rep 15: 1469-75.

6. Kauer WK, Stein HJ (2010) Emerging concepts of bile reflux in the constellation of gastroesophageal reflux disease. J Gastrointest Surg 14 Suppl 1: S9-16.

7. Cheng P, Li JSh, Gong J, Zhang LF, Chen RZ (2011) Effects of refluxate pH values on duodenogastroesophageal reflux-induced esophageal adenocarcinoma. World J Gastroenterol 17: 3060-5.

8. Theisen J, Peters JH, Fein M, Hughes M, Hagen JA, et al. (2005) The mutagenic potential of duodenoesophageal reflux. Ann Surg 241: 63-8.

9. Dvorak K, Payne CM, Chavarria M, Ramsey L, Dvorakova B, et al. (2007) Bile acids in combination with low pH induce oxidative stress and oxidative DNA damage: relevance to the pathogenesis of Barrett's oesophagus. Gut 56: 763-71.

10. Jolly AJ, Wild CP, Hardie LJ (2009) Sodium deoxycholate causes nitric oxide mediated DNA damage in oesophageal cells. Free Radic Res 43: 234-40.

11. Zhang R, Gong J, Wang H, Wang L (2005) Bile salts inhibit growth and induce apoptosis of culture human normal esophageal mucosal epithelial cells. World J Gastroenterol 11: 6466-71.

12. Dvorakova K, Payne CM, Ramsey L, Bernstein H, Holubec H, et al. (2005) Apoptosis resistance in Barrett's esophagus: ex vivo bioassay of live stressed tissues. Am J Gastroenterol 100: 424-31.

13. Bernstein H, Bernstein C, Payne CM, Dvorak K (2009) Bile acids as endogenous etiologic agents in gastrointestinal cancer. World J Gastroenterol 15: 3329-40. 14. Peters JH, Avisar N (2010) The molecular pathogenesis of Barrett's esophagus: common signaling pathways in embryogenesis metaplasia and neoplasia. J Gastrointest Surg 14 Suppl 1: S81-7. 14. Peters JH, Avisar N (2010) The molecular pathogenesis of Barrett's esophagus: common signaling pathways in embryogenesis metaplasia and neoplasia. J Gastrointest Surg 14 Suppl 1: S81-7.

15.Miyashita T, Miwa K, Fujimura T, Ninomiya I, Fushida S, Shah FA, Harmon JW, Hattori T, Ohta T (2013) The severity of duodeno-esophageal reflux influences the development of different histological types of esophageal cancer in a rat model. Int J Cancer 132: 1496-504.

16. Johnson DA, Levy BH 3rd (2010) Evolving drugs in gastroesophageal reflux disease: pharmacologic treatment beyond proton pump inhibitors. Expert Opin Pharmacother 11: 1541-8.

17. Pace F, Riegler G, de Leone A, Dominici P, Grossi E, et al. (2011) Gastroesophageal reflux disease management according to contemporary international guidelines: A translational study. World J Gastroenterol 7: 1160-6.

18. Duman M, Özer M, Reyhan E, Demirci Y, Atıcı AE, et al. (2011) In vitro effect of pantoprazole on lower esophageal sphincter tone in rats. World J Gastroenterol 17: 5105-9.

19. Duman M, Polat E, Ozer M, Demirci Y, Yasar NF, et al. (2013) The Effect of Rabeprazole on LES Tone in Experimental Rat Model. J Invest Surg 26: 186-90.

20. Kahrilas PJ, Shaheen NJ, Vaezi MF, Hiltz SW, Black E, et al. (2008) American Gastroenterological Association medical position statement on the management of gastroesophageal reflux disease. Gastroenterology 135: 1392-413.

21. Boeckxstaens GE, Rydholm H, Lei A, Adler J, Ruth M (2010) Effect of lesogaberan, a novel GABA-receptor agonist, on transient lower esophageal sphincter relaxations in male subjects. Aliment Pharmacol Ther 11: 1208-17.

22. Piazuelo E, Santander S, Cebrián C, Jiménez P, Pastor C, et al. (2012) Characterization of the prostaglandin E2 pathway in a rat model of esophageal adenocarcinoma. Curr Cancer Drug Targets 12: 132-43.

23. Hashimoto N (2012) Expression of COX2 and p53 in Rat Esophageal Cancer Induced by Reflux of Duodenal Contents. ISRN Gastroenterol $2012: 914824$.

24. Hashimoto N (2014) Effects of bile acids on cyclooxygenase-2 expression in a rat model of duodenoesophageal anastomosis. World J Gastroenterol 7: 20: 6541-6. 25. Oyama K, Fujimura T, Ninomiya I, Miyashita T, Kinami S, et al. (2007) Cyclooxygenase (COX)-2 expression in a rat duodenoesophageal reflux model and chemoprevention of adenocarcinoma by the selective COX-2 inhibitor nimesulide. Nihon Shokakibyo Gakkai Zasshi 104: 1183-91. 
26. Selvan B, Ramachandran A, Korula A, Amirtharaj GJ, Kettimuthu K, et al. (2012) Low dose aspirin prevents duodenoesophageal reflux induced mucosal changes in wistar rat esophagus by MAP kinase mediated pathways. Int J Surg 10: 73-9.

27. Mas R (2001) D-002: A product obtained from beeswax. Drugs of the Future 26: 731-44.

28. Zamora Z, Molina V, Mas R, Ravelo Y, Pérez Y, et al. (2014) Protective effects of D-002 on experimentally induced gastroesophageal reflux in rats. World J Gastroenterol 20: 2085-90.

29. Zamora Z, Molina V, Mas R, Ravelo Y, Pérez Y, et al. (2015) D-002 treatment attenuates esophagitis in a model of chronic gastro-esophagealreflux in rats. IOSR Journal Of Pharmacy 5: 36-40.

30. Zamora Z, Molina V, Mas R, Ravelo Y (2015) Effects of D-002 (Beeswax Alcohols) on esophagitis induced by duodenoesophageal and duodenogastroesophageal reflux in rats. Int J Pharmacol Toxico 5: 146-51.

31. Noa M, Mas R, Mendoza S, Zamora Z, Molina V, Valle M (2016) D-00 2 Ameliorates Histological Changes in Rats with Bile Reflux-Induced Esophagitis. Int J Pharmacol Phytochemistry Ethnomedizin 6: 72-81.

32. Canadian Council on Animal Care (1993) Guide to the Care and Use of Experimental Animals. Vol 1, 2nd edn 1993.

33. Chen X, Li N, Wang S, Hong J, Fang M, et al. (2002) Aberrant arachidonic acid metabolism in esophageal adenocarcinogenesis, and the effects of sulindac, nordihydroguaiaretic acid, and $\alpha$-difluoromethylornithine on tumorigenesis in a rat surgical model. Carcinogenesis 23: 2095-102.

34. Marxwell MA, Haas SM, Beiber LL, Tolbert NE (1989) A modification of the Lowry procedure to simplify protein determination in membrane lipoprotein samples. Anal Biochem 87: 206-10.

35. Ohkawa H, Ohishi N, Yagi K (1979) Assay for lipid peroxides in animal tissues by the thiobarbituric acid reaction. Anal Biochem 95: 351-8.

36. Inayama M, Hashimoto N, Tokoro T, Shiozaki H (2007) Involvement of oxidative stress in experimentally induced reflux esophagitis and esophageal cancer. Hepatogastroenterology 54: 761-5.

37. Pérez Y, Oyarzabal A, Mas R, Molina V, Jiménez S (2013) Protective effect of D-002, a mixture of beeswax alcohols, against indomethacin-induced gastric ulcers and mechanism of action. J Nat Med 67: 182-9.

38. Singh P, Singh N, Sengupta S, Palit G (2012) Ameliorative effects of Panax quinquefolium on experimentally induced reflux oesophagitis in rats. Indian J Med Res 135: 407-13.

39. Xu Y, Zhu J, Hu X, Wang C, Lu D, et al. (2016) CLIC1 Inhibition Attenuates Vascular Inflammation, Oxidative Stress, and Endothelial Injury. PLoS ONE 11: e0166790.

40. Renu N, Kaithwas G, Ramteke PW, Saraf SA (2012) Effect of Linum usitatissimum (linseed/flaxseed) fixed oil on experimental esophagitis in albino rats. Acta Gastroenterol Belg 75: 331-5.

41. Byrnes CK, Bahadursingh A, Akhter N, Parinandi NL, Natarajan V, et al. (2003) Duodenal Reflux Produces Hyperproliferative Epithelial Esophagitis-A Possible Precursor to Esophageal Adenocarcinoma in the Rat. J Gastrointest Surg 7: 172-80.

42. Inayama M, Hashimoto N, Tokoro T, Shiozaki H (2007) Involvement of oxidative stress in experimentally induced reflux esophagitis and esophageal cancer. Hepatogastroenterology 54: 761-5.

43. Giri AK, Rawat JK, Singh M, Gautam S, Kaithwa G (2015) Effect of lycopene against gastroesophageal reflux disease in experimental animals. BMC Complement Alter Med 15: 110.

44. Shin MR, An HJ, Seo BI, Roh SS (2017) Anti-apoptotic effect of banhasasim-tang on chronic acid reflux esophagitis. World J Gastroenterol 23: 4644-53.

45. Kruel CRP, Pinto LFR, Blanco TCM, Barja-Fidalgo TC, Melo LL, et al. (2010) Evaluation of the heme oxygenase-1 expression in esophagitis and esophageal cancer induced by different reflux experimental models and diethylnitrosamine. Acta Cir Bras 25: 304-10.

46. Pérez Y, Oyarzábal A, Ravelo Y, Mas R, Jiménez S, Molina V (2014) Inhibition of Ciclooxigenase and 5-Lipooxigenase enzymes by D-002 (beeswax alcohols). Curr Top Nutr Res 12: 13-8.

47. Kusaka G, Uno K, Iijima K, Shimosegawa T (2016) Role of nitric oxide in the pathogenesis of Barrett's-associated carcinogenesis. World J Gastrointest Pathophysiol 7: 131-7. 